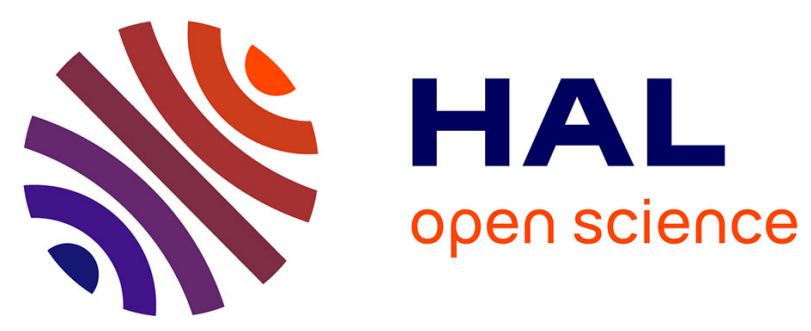

\title{
A hybrid process combining oxygen enriched air combustion and membrane separation for post-combustion carbon dioxide capture
}

Eric Favre, Roda Bounaceur, Denis Roizard

\section{- To cite this version:}

Eric Favre, Roda Bounaceur, Denis Roizard. A hybrid process combining oxygen enriched air combustion and membrane separation for post-combustion carbon dioxide capture. Separation and $\mathrm{Pu}-$ rification Technology, 2009, 68 (1), pp.30-36. 10.1016/j.seppur.2009.04.003 . hal-01168988

\section{HAL Id: hal-01168988 \\ https://hal.science/hal-01168988}

Submitted on 20 Feb 2020

HAL is a multi-disciplinary open access archive for the deposit and dissemination of scientific research documents, whether they are published or not. The documents may come from teaching and research institutions in France or abroad, or from public or private research centers.
L'archive ouverte pluridisciplinaire HAL, est destinée au dépôt et à la diffusion de documents scientifiques de niveau recherche, publiés ou non, émanant des établissements d'enseignement et de recherche français ou étrangers, des laboratoires publics ou privés.

\section{(c)(1)}

Distributed under a Creative Commons Attribution| 4.0 International License 


\title{
A hybrid process combining oxygen enriched air combustion and membrane separation for post-combustion carbon dioxide capture
}

\author{
Eric Favre*, Roda Bounaceur, Denis Roizard \\ Nancy Université, Laboratoire des Sciences du Génie Chimique UPR CNRS 6811, 1 rue Grandville, BP 541, 54001 Nancy, France
}

For carbon dioxide capture and storage (CCS), similar to a large majority of industrial processes, the separation (i.e. capture) step dominates the costs of the technological chain. Based on a concept of mini-mal work of concentration, the evaluation of a tentative capture framework which combines an oxygen enrichment step before combustion and a $\mathrm{CO}_{2}$ capture step from flue gas has been investigated through a simulation study. The performances of a cryogenic oxygen production process have been used for the upstream part, while a membrane separation process based on $\mathrm{CO}_{2}$ selective materials has been investi-gated for $\mathrm{CO}_{2}$ capture. The potentialities of this hybrid process from the energy requirement point of view are discussed. It is shown that the hybrid process can lead to a 35\% decrease of the energy requirement (expressed in GJ per ton of recovered $\mathrm{CO}_{2}$ ) compared to oxycombustion, providing optimal operating conditions are chosen.

\section{Introduction}

The achievement of significant reductions in greenhouse gas emissions from the transportation, residential, energy and industry sectors is a formidable scientific and technological challenge $[1,2]$. For large scale emission points (such as power plants, steel, cement or petrochemicals plants), numerous Carbon Capture and Sequestration (CCS) strategies have been already proposed and are currently investigated in order to identify the most appropriate solution, from the technico-economical point of view. Basically, two major options can be considered (Fig. 1) in that case:

i) A first option, usually called post-combustion capture, consists in separating $\mathrm{CO}_{2}$ from the products of combustion using conventional (i.e. chemical solvent scrubbing [3]) or novel approaches (Fig. 1a).

ii) Another alternative, called oxycombustion or $\mathrm{O}_{2} / \mathrm{CO}_{2}$ recycle combustion, involves burning the fuel (natural gas, coal, oil, biomass. ..) with oxygen (typically 95-99\% purity) in an atmosphere of recycled flue gas (Fig. 1b). The diluting effect exerted by nitrogen is thus circumvented and a $90 \%$ purity $\mathrm{CO}_{2}$ can be obtained after drying [4].

Two major constraints are usually applied to the carbon capture problem [1]: the $\mathrm{CO}_{2}$ capture ratio $(R)$ of the technological chain

\footnotetext{
* Corresponding author. Tel.: +33 3831753 90; fax: +33 383322975

E-mail address: Eric.Favre@ensic.inpl-nancy.fr (E. Favre).
}

should be high (typically $90 \%$ or more), and $\mathrm{CO}_{2}$ purity should be high enough (typically 90\%) in order to minimize compression and transportation costs. From the technico-economical point of view, the energy requirement of the carbon capture approach, usually expressed in $\mathrm{GJ}$ per ton of recovered $\mathrm{CO}_{2}$, should be as low as possible. Different target data can be found, for instance in the carbon capture and sequestration roadmaps which have been published by different countries. A target of $2 \mathrm{GJ} /$ ton is often mentioned and it corresponds to the recommendations of the European Union, for instance [5]. It can be taken as an average figure.

Surprisingly, the two options sketched in Fig. 1 have always been seen as distinct and, somehow, competing. It could be however that a combination of enriched oxygen combustion and postcombustion capture shows interesting performances. We report hereafter a study which aims to explore such a hybrid approach. In a first step, a theoretical development of the potential interest of a dual process is proposed. A simulation study is then described and discussed for a natural gas power plant.

\section{Rationale}

The starting point of the analysis proposed in this study makes use of the minimal work of separation concept. For a gaseous ideal binary mixture, the theoretical and unattainable minimal work of separation, for constant temperature and pressure conditions, can be easily computed from the composition (mole fraction, $x$ ) of the mixture through [6]:

$W_{\min }=-\Re T[x \ln (x)+(1-x) \ln (1-x)]$ 
(a)

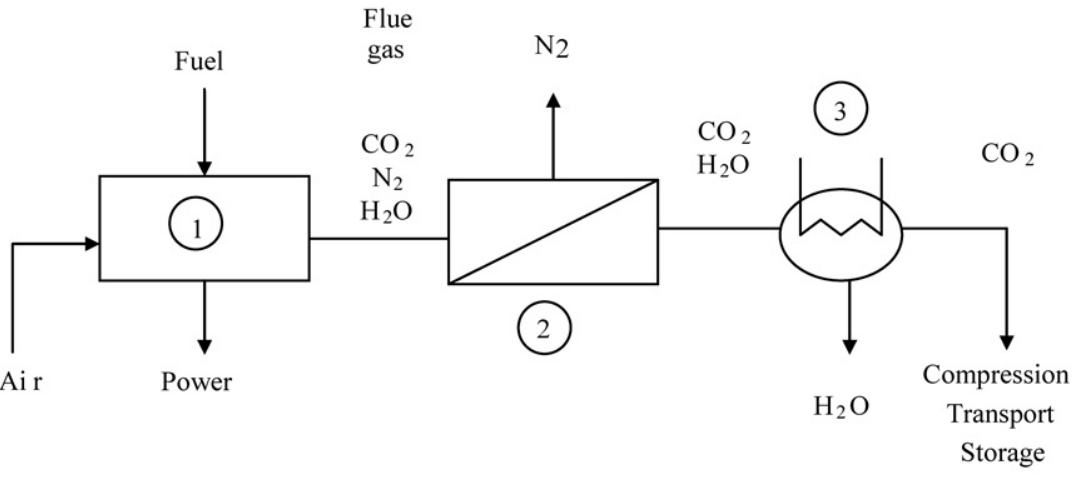

(b)

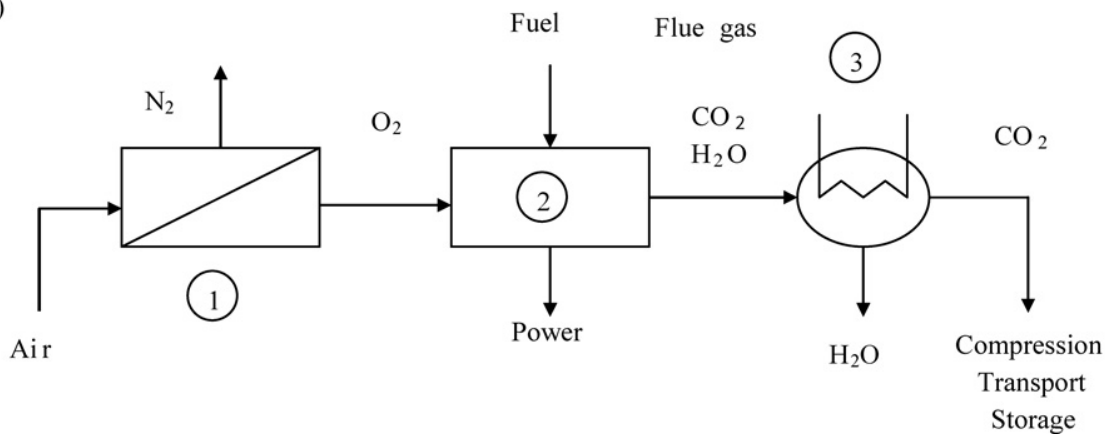

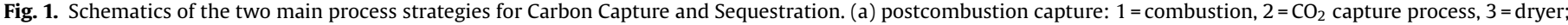
(b) Oxycombustion: 1 = oxygen production process (cryogenics, PSA. . ), 2 = combustion, $3=$ dryer.

The above expression assumes a constant temperature and pressure process, and an ideal mixture behaviour from the thermodynamics point of view. This latter hypothesis is classically postulated to hold for the gases and operating conditions which prevail in oxycombustion or post-combustion capture.

It is worth stressing two points at this stage:

i) The calculation expressed through Eqn. (1) assumes a reversible process, while mass and energy transfer are obviously irreversible. Nevertheless, Eqn. (1) remains often used in order to assess to what extent the real work of separation differs from $W_{\text {min }}$. The ratio between these two entities is often called the overall efficiency $\eta$ of the separation process [6]. Even though more sophisticated approaches can be proposed (e.g. based on energy quality or energy concepts), this basic estimation gives an idea of energy degradation when a separation process is applied. Table 1 summarizes the major characteristics for the oxycombustion and the post-combustion situation. It can be seen that $\eta$ is typically in the range of a few percent for these two technologies. Similar orders of magnitude have been obtained for

Table 1

Overview and key variables of the two main situations for carbon dioxide postcombustion capture $[3,4]$. The minimal work of separation has been computed for ambient temperature and pressure conditions. Membrane separations, which are usually not considered as an adequate technology for postcombustion carbon dioxide capture, will be investigated in this study.

\begin{tabular}{lll}
\hline & Oxycombustion & Postcombustion \\
\hline Mixture & $\mathrm{O}_{2} / \mathrm{N}_{2}$ & $\mathrm{CO}_{2} / \mathrm{N}_{2}$ \\
$\%$ & $21 / 79$ & $5 / 95$ to $30 / 70$ \\
$P(\mathrm{Bar})$ & 1 & 1 \\
$T\left({ }^{\circ} \mathrm{C}\right)$ & 20 & $50-200$ \\
$W_{\min }\left(\mathrm{kJ} \mathrm{mol}^{-1}\right)$ & 1.4 & $0.5-1.7$ \\
Best available technology & Cryogenics & $\begin{array}{l}\text { Absorption in a } \\
\text { chemical solvent }\end{array}$ \\
Energy requirement $\left(\mathrm{MJ} /\right.$ ton of $\mathrm{O}_{2}$ or $\left.\mathrm{CO}_{2}\right)$ & 0.9 & $2-4$ \\
Energy efficiency, $\eta$ & $\sim 0.03$ & $\sim 0.04$ \\
\hline
\end{tabular}

distillation columns, for instance. Nevertheless, $\eta$ values down to $10^{-5}$ can be observed for very difficult separations, such as the isotope fractionation $\mathrm{U}^{235} \mathrm{~F}_{6} / \mathrm{U}^{238} \mathrm{~F}_{6}$ in the nuclear sector [7]. This basic analysis shows that the efficiency of chemical absorption and cryogenic processes is comparable to other industrial operations in terms of overall energy efficiency, but it also shows that a significant improvement remains theoretically possible.

ii) The computation expressed in Eqn. (1) refers to a separation process which ends up with two pure compounds. In a great number of cases, one target compound only has to be extracted and concentrated up to a given purity. The CCS framework obviously belongs to this category, carbon dioxide (for postcombustion capture) or oxygen (for oxycombustion) being the target compound in the flue gas or in air, respectively. In that case, Eqn. (1) has to be rewritten such as what could be called the minimal work of extraction for one mole of pure compound only (i.e. the target compound) is calculated:

$W_{\min }^{\prime}=-\Re T\left[\frac{x \ln (x)+(1-x) \ln (1-x)}{x}\right]$

Fig. 2 shows the pattern of minimal work of extraction $W_{\min }^{\prime}$ under ambient temperature conditions for an ideal binary mixture. The approximate logarithmic dependency between the energy requirement for separation and the concentration of the target compound in the feed mixture, which is often proposed as a rule of thumb for diluted mixtures separations [7], is easily highlighted thanks to this approach. For illustrative purposes, oxycombustion (production of pure $\mathrm{O}_{2}$ from a $21 \%$ mixture), postcombustion (production of pure $\mathrm{CO}_{2}$ from a $\sim 10 \%$ mixture) and direct extraction of $\mathrm{CO}_{2}$ from air (feed composition $\sim 350 \mathrm{ppmv} \mathrm{CO}_{2}$ ) have been added.

Even though the minimal work of extraction concept appears to be more appropriate for the CCS situation, it is possible to develop a more refined analysis which will be detailed hereafter. The starting point concerns the target $\mathrm{CO}_{2}$ purity which is needed in order to enable transportation and sequestration. Several guidelines can be indeed found in the literature, ranging between 70 [8] and maxi- 


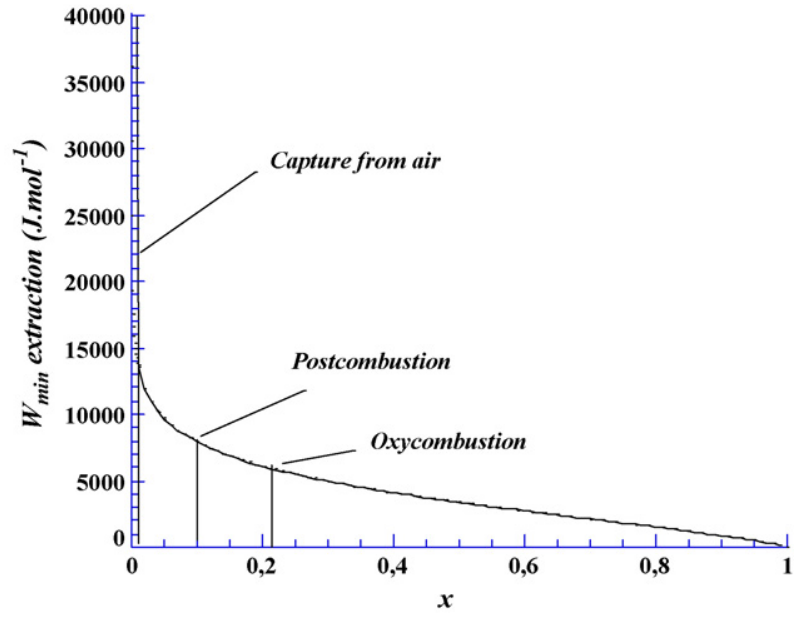

Fig. 2. Minimal work of extraction $\mathrm{W}_{\min }^{\prime}$ (Eqn. (2)) at $298.15 \mathrm{~K}$ for an ideal binary mixture. $\mathrm{A} \mathrm{CO}_{2} / \mathrm{N}_{2}$ mixture is assumed for the capture of $\mathrm{CO}_{2}$ from air and for postcombustion. Oxycombustion takes into account the production of pure oxygen from air (i.e. $21 \% \mathrm{O}_{2}$ ).

mal (i.e. >99\%) values [1]. Such a broad range should logically play a key role in the corresponding work of separation but it cannot be explicitly expressed based on what has been exposed before (Eqs. (1) and (2)). If we start from a $\mathrm{CO}_{2}$ mole fraction $\mathrm{x}$ in a feed mixture and if we want to achieve a final mole fraction $y$ of this target compound, the corresponding minimal work, which could be named work of concentration $W^{\prime \prime}$, can be expressed as

$W_{\min }^{\prime \prime}=-\Re T\left[\frac{x \ln (x)+(1-x) \ln (1-x)}{x}-\frac{y \ln (y)+(1-y) \ln (1-y)}{y}\right]$

Eqn. (3) can be easily derived from a combination of two virtual separation steps starting from $x$ and $y$, respectively, each computed through Eqn. (2). Fig. 3 shows a series of curves of the minimal work of concentration for an ideal binary mixture with a target mole fraction $(y)$ ranging from 0.5 to 1 . Logically, a less stringent target purity requires a lower minimal concentration work. For instance, a concentration operation up to maximal purity (i.e. $y=1$ ) from a $10 \%$ feed mixture (i.e. $x=0.1$ ), typical of the actual postcombus-

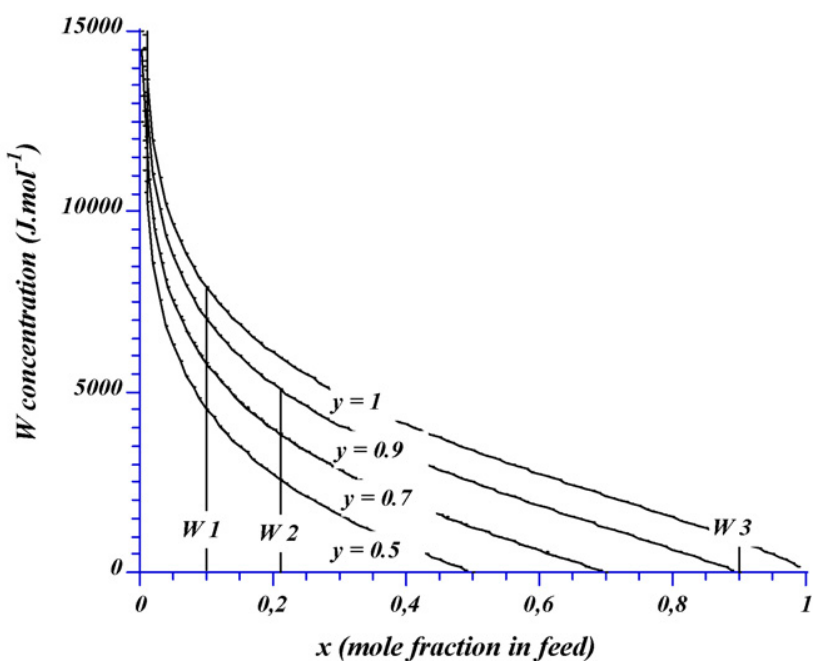

Fig. 3. Minimal work of concentration $\mathrm{W}_{\min }^{\prime \prime}$ (Eqn. (3)) at $298.15 \mathrm{~K}$ for an ideal binary mixture. Comparison of the separation work associated to a postcombustion capture with $10 \%$ carbon dioxide in flue gas (W1), with a process which would combine an oxygen enrichment step from air to 0.9 mole fraction for combustion (W2) and a capture step performed on a concentrated $\mathrm{CO}_{2}$ flue gas (W3). tion capture strategy, requires $27 \%$ more theoretical concentration energy than a concentration which is limited up to $70 \%$ mole fraction (often presented as the lowest acceptable concentration which fulfils transportation constraints for CCS).

Even though the methodology sketched above remains extremely simple, it suggests that an alternative approach to the carbon capture problem, which is the key concept explored in this paper, could be tested. This approach can be exposed as follows: a single separation process dedicated to oxygen purification (oxycombustion situation) or $\mathrm{CO}_{2}$ postcombustion capture, such as those shown in Fig. 1, requires a significant amount of energy since a high purity is desired, starting from a diluted feed stream (a value close the one, given by the curve $y=1$ from the minimal work of concentration approach, is desired). Could it be that a combination of a separation process with a moderate enrichment of oxygen on the upstream part of the combustion process, associated to a postcombustion capture process treating a flue gas with a high mole fraction of $\mathrm{CO}_{2}$, would have any chance to require less energy than the two first options? This hybrid approach is sketched in Fig. 3. A classical postcombustion capture process with a $10 \%$ mole fraction of $\mathrm{CO}_{2}$ in the gas mixture corresponds to a minimal work of concentration $\mathrm{W} 1$, while a combination of a partial oxycombustion (i.e. oxygen enrichment) step and a carbon dioxide capture process would require a total work W2 (production of a 90\% mole fraction oxygen feed mixture from air for combustion) + W3 (concentration of a $90 \%$ mole fraction carbon dioxide mixture to maximal purity). For sake of simplicity, an isothermal process has been assumed at this stage. It is important to stress that a specific parameter has to be taken into account in order to quantitatively link the two separation works (i.e. a given factor between the mole fraction of oxygen at the inlet of the combustion process and the carbon dioxide mole fraction in the dry flue gas is needed). This factor is assumed to be one for Fig. 3 but a more rigorous development will be exposed hereafter.

More generally, it is obvious that the above analysis remains questionable since it does not take into account the differences in energy efficiency among the different separation processes (in other words, the same process efficiency $\eta$ has been assumed in order to enable a direct comparison in Fig. 3). Nevertheless, a large range of situations, with different values of the target final $\mathrm{CO}_{2}$ purity, different $\mathrm{CO}_{2}$ contents in flue gas, different process efficiencies, different target oxygen concentrations of the oxygen enrichment step can be investigated according to this common framework. We develop hereafter a case study based on a simulation of a hybrid enriched oxygen/carbon capture process, in order to more rigorously evaluate the potential interest of this concept.

\section{Hybrid process description}

A general scheme of a hybrid process which combines an enriched oxygen production step and a carbon dioxide capture step (performed on the dry flue gas) is shown in Fig. 4.

In order to achieve an overall analysis of the process, it is first necessary to identify how to link the oxygen mole fraction $\mathrm{x}$ on the feed side, with the carbon dioxide mole fraction $x^{\prime}$ in the dry flue gas, on the downstream side. This question can be solved as soon as the chemical reaction of combustion is defined. For instance, for saturated hydrocarbons, the general equation for a perfect combustion process can be written:

$\mathrm{C}_{n} \mathrm{H}_{2 n+2}+(1.5 n+0.5) \mathrm{O}_{2} \rightarrow n \mathrm{CO}_{2}+(n+1) \mathrm{H}_{2} \mathrm{O}$

Taking into account the fact that a given fraction of the feed stream contains nitrogen, the $\mathrm{CO}_{2}$ content in the dry flue gas $\mathrm{x}^{\prime}$ can be expressed from the oxygen mole fraction in the feed stream $(x)$ 


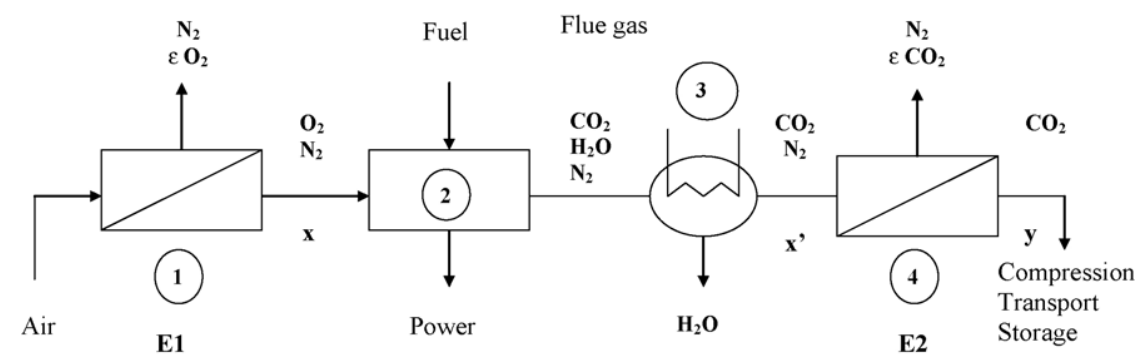

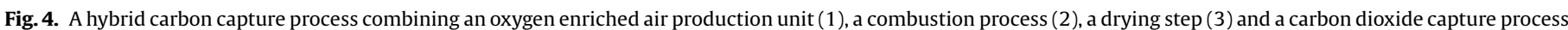

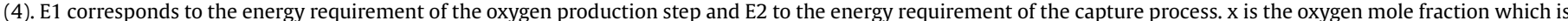
injected in the combustion chamber, $x^{\prime}$ the $\mathrm{CO}_{2}$ mole fraction in the dry flue gas and $y$ the $\mathrm{CO}_{2}$ mole fraction which is recovered for transportation and sequestration.

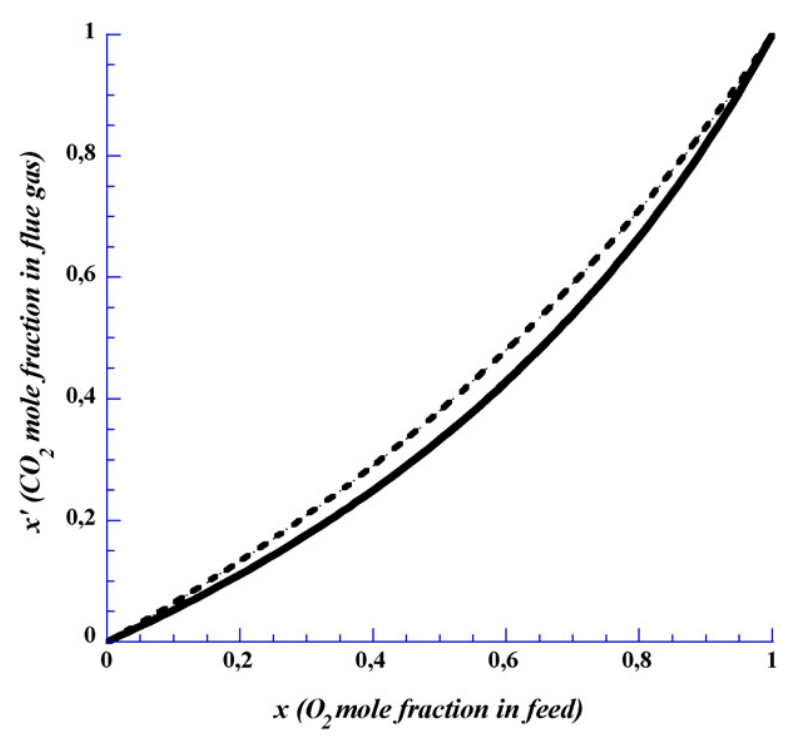

Fig. 5. Relationship between the oxygen content in the feed mixture $(x)$ and the corresponding $\mathrm{CO}_{2}$ content in the dry flue gas $\left(x^{\prime}\right)$ for saturated hydrocarbons. Bold line: methane $(n=1)$. Dotted line: butane and heavier hydrocarbons $(n>4)$.

through

$x^{\prime}=\left[\frac{2 n x /(3 n+1)}{(2 n x /(3 n+1))+1-x}\right]$

This expression shows that for saturated hydrocarbons, the mole fraction of $\mathrm{CO}_{2}$ in the dry flue gas $\left(x^{\prime}\right)$ will systematically be smaller than the mole fraction of oxygen in the feed stream $(x)$. Fig. 5 shows the relationship between the two variables $x^{\prime}$ and $x$.

It can be seen that a combustion plant fed with methane $(n=1)$ and with an equimolar oxygen/nitrogen mixture $(x=0.5)$ will produce a dry flue gas with $33 \%$ mole fraction $\mathrm{CO}_{2}\left(x^{\prime}=0.33\right)$.

It is possible at this stage to investigate a series of situations for which the two strategies defined before (postcombustion capture $=\mathrm{W} 1$ or hybrid approach $=\mathrm{W} 2+\mathrm{W} 3$ ) are compared. A major unknown remains at this stage, namely the energy efficiency $\eta$ of the different separation processes. In order to investigate more specifically this effect, the two separation processes have obviously to be defined.

\section{Case study simulation}

The performances of a hybrid process, based on a combined oxygen enriched combustion and carbon dioxide capture concept (sketched in Fig. 4), have been investigated through a simulation study as follows: i) Cryogenic oxygen production has been selected for the upstream part (noted 1 in Fig. 4). This technology is known indeed to offer the best performances for large scale oxygen production $[9,10]$. Moreover, the effective energy requirement of this process, as a function of the oxygen purity, has been reported and is shown in Fig. $6[10,11]$. Other oxygen production technologies such as Pressure Swing Adsorption PSA [12] or gas separation membranes [13-15] could be also proposed. Nevertheless, preliminary computations showed that the energy requirement for these techniques is larger than the cryogenics characteristics. Oxygen enrichment by membrane has been studied in detail for improved combustion processes [16]. The limitations of materials selectivity (which do not allow an oxygen purity larger than $40 \%$ ) and the too low membrane permeability make this option unsuitable.

ii) A gas permeation membrane module has been selected for the carbon dioxide concentration step (noted 4 in Fig. 4). Even though membrane operation is often claimed to be very interesting from the energy efficiency point of view [17,18], studies dedicated to this type of separation process in CCS are scarce [19-21]. Nevertheless, preliminary studies have shown that the energy efficiency of membrane processes is expected to largely increase when concentrated $\mathrm{CO}_{2}$ flue gases (typically above $30 \%$ ) have to be treated [22]. Moreover, the energy requirement of a gas permeation membrane module can be easily computed, through well established models [22,23].

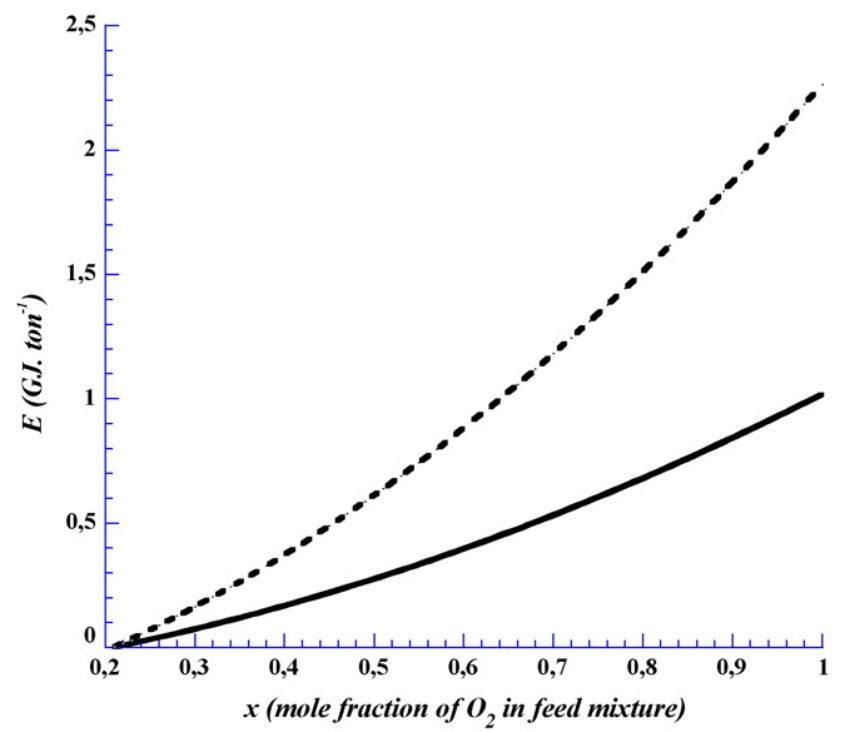

Fig. 6. Energy requirement (in GJ per ton) for enriched oxygen production vs oxygen purity. Bold line: expressed in GJ per ton of oxygen at the inlet of the combustion process $\mathrm{E}_{\mathrm{O} 2}$ (from [10]). Dotted line: expressed in GJ per ton of carbon dioxide produced at the exit of a combustion process with methane as fuel (computed using Eqn. (5)). 
The simulation study has been performed as follows:

i) Natural gas (assumed to be pure methane) has been selected as model fuel.

ii) A defined value of oxygen mole fraction (typically between $40 \%$ and 99\%) $x$ is imposed at the upstream side.

iii) The stoichiometry of combustion allows the $\mathrm{CO}_{2}$ content in the dry flue gas $x^{\prime}$ to be computed, according to Eqn. (5).

iv) The energy requirement of the membrane process is further computed according to a methodology that has been detailed elsewhere [22]. A defined $\mathrm{CO}_{2}$ purity (noted y and ranging between 0.9 and 0.95 ) and a target carbon dioxide recovery ratio (noted $R$ and fixed at either 0.9 or 0.95 ) have to be chosen in order to achieve that purpose. Membrane $\mathrm{CO}_{2} / \mathrm{N}_{2}$ selectivity $(\alpha)$ was first fixed at 50 , which is representative of existing most selective polymeric membrane materials [21]. Increased selectivity values (100 and 200) where further investigated in order to explore the incidence of improved membrane performances, within the range of so called trade-off characteristics for dense polymers [21]. A target pressure ratio (ratio of the upstream and downstream pressure of the membrane module), can then be determined through numerical resolution.

v) The overall energy requirement of the hybrid process, noted $E$ and expressed in $\mathrm{GJ}$ per ton of $\mathrm{CO}_{2}$ recovered, can be finally determined as the sum of the oxygen production part $\left(E_{1}\right)$ and the $\mathrm{CO}_{2}$ capture part $\left(E_{2}\right)$ through

$$
E=E 1+E 2=\frac{E_{\mathrm{O} 2}}{R} \frac{3 n+1}{2 n}+\frac{\gamma}{\gamma-1} \frac{\Re T}{\eta^{\prime}}\left[\left(\frac{P^{\prime}}{P^{\prime \prime}}\right)^{\gamma-1 / \gamma}-1\right] \frac{10^{-3}}{R x^{\prime} 44}
$$

$\mathrm{E}_{\mathrm{O} 2}$ is the energy requirement per ton of oxygen for a given purity (shown as a bold line in Fig. 6). $\gamma$ is the adiabatic expansion coefficient of the $\mathrm{CO}_{2} / \mathrm{N}_{2}$ mixture, $R$ the carbon dioxide capture ratio, $\Re$ the perfect gas constant, $x^{\prime}$ the flue gas carbon dioxide mole fraction and $T$ the module temperature. The compressor isentropic efficiency $\left(\eta^{\prime}\right)$ has been fixed at 0.85 , according to classical performances of dry compression operations [19,24] and $n$ fixed to 1 (methane). The above expression assumes a compression step

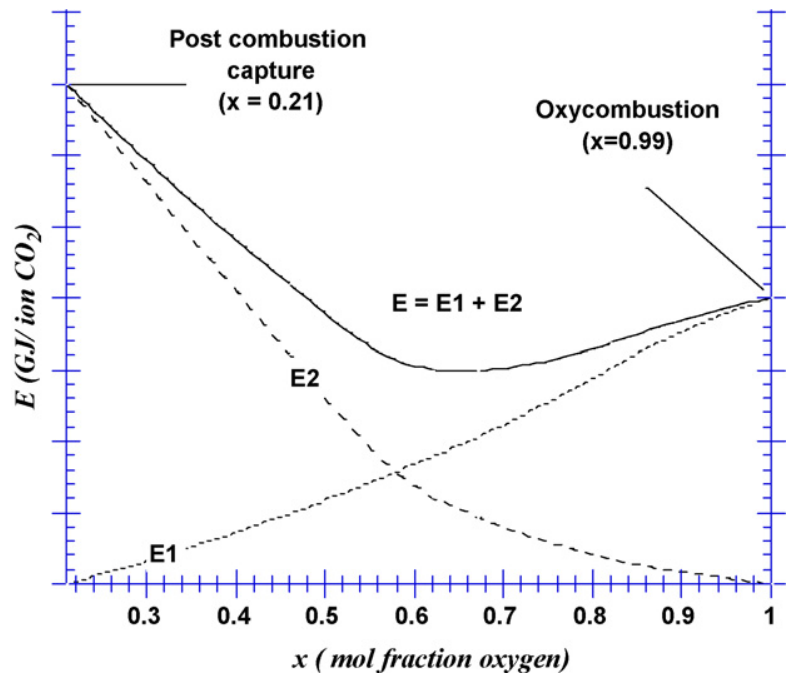

Fig. 7. Schematic pattern of the energy requirement for oxygen production (E1), for carbon dioxide capture by a membrane module (E2) and overall energy requirement of a hybrid process $(E=E 1+E 2)$, as a function of the oxygen mole fraction in the feed stream of the combustion unit $(x)$. Positions corresponding to the postcombustion capture and oxycombustion situation have been added. This graph is a qualitative reading grid which can be used for the analysis of the simulation results of the hybrid process. performed on the dry flue gas flowstream. Carbon dioxide is thus recovered at a purity y ( 0.9 or 0.95 mole fraction), at the temperature of the process $(T=303 \mathrm{~K})$ and under atmospheric pressure. This strategy enables a comparison with classical postcombustion capture processes, such as absorption in a chemical solvent, for which the slightly similar T and $\mathrm{P}$ conditions are obtained after the solvent regeneration and drying step.

Fig. 7 shows a qualitative overview of the expected patterns for $\mathrm{E} 1, \mathrm{E} 2$ and $\mathrm{E}$. The possible occurrence of an optimum, which is a key question addressed in this study, will have to be first checked on simulation data.

Fig. 8 summarizes the results of the simulation for two different targets:

(i) $90 \%$ capture ratio $(R=0.9)$ and $\mathrm{CO}_{2}$ purity ( $y$ ) of 0.9 (Fig. $8 \mathrm{a}$ )

(ii) $95 \%$ capture ratio $(R=0.95)$ and $\mathrm{CO}_{2}$ purity (y) of 0.95 (Fig. $8 \mathrm{~b}$ )

It can be seen that an optimal oxygen purity, leading to a minimal overall energy requirement, can be clearly determined according this approach. The validity of the minimal energy of separation based on the association of two distinct steps, suggested through Fig. 3, is thus confirmed.
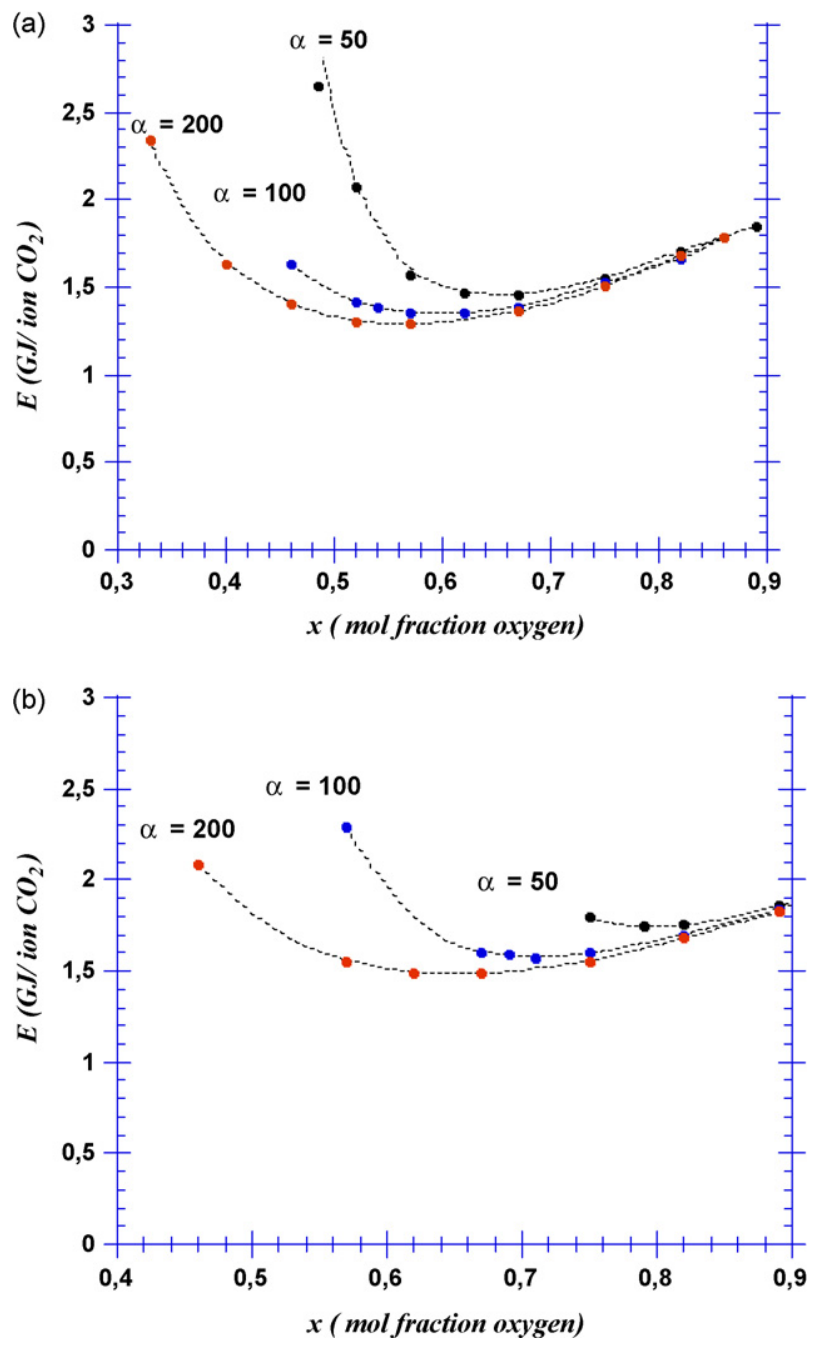

Fig. 8. Overall energy requirement of a hybrid process $(E=E 1+E 2)$, in $G J$ per ton of $\mathrm{CO}_{2}$ recovered as a function of the oxygen mole fraction in the feed stream of the combustion unit $(x)$. Each curve corresponds to a given membrane selectivity $(\alpha=50$ or 100 or 200). Points correspond to simulation results, dotted lines to interpolations. Capture ratio $R=0.9$ and $\mathrm{CO}_{2}$ purity on the permeate side $(y)=0.9$; capture ratio $R=0.95$ and $\mathrm{CO}_{2}$ purity on the permeate side $(y)=0.95$. 
The location of the minimal overall energy requirement, expressed in $\mathrm{O}_{2}$ mole fraction in the feed mixture, ranges roughly between 0.5 and 0.6 for moderate recovery constraints $(R=0.9$ and $y=0.9$, Fig. 8a). A shift towards a higher purity range (0.6-0.8) is observed when a higher recovery and a higher purity are imposed $(R=0.95, y=0.95$, Fig. $8 \mathrm{~b})$. Furthermore, more selective membrane materials systematically lead to lower optimal oxygen purity data, and lower overall energy requirements. This differs strongly with the role of selectivity for a classical postcombustion membrane application, for which an almost negligible influence of membrane selectivity has been reported, as soon as it exceeds 50 [22]. The search for more selective membrane materials could thus be seen as extremely interesting in the hybrid situation investigated in this study, which corresponds to concentrated carbon dioxide feed mixtures (typically 0.4-0.65 mole fraction). Unfortunately, experimental membrane permeation data under these feed conditions are scarce. Last but not least, taking $1.8 \mathrm{GJ}$ per ton of $\mathrm{CO}_{2}$ as a classical energy requirement for oxycombustion with natural gas as fuel [4], the hybrid process proposed in this study can lead to a $22-35 \%$ decrease in terms of overall energy requirement.

\section{Conclusion and prospects}

The objective of this study was to explore the potential interest of a hybrid process for postcombustion carbon dioxide capture. Starting from the concept of minimal work of concentration, a simulation has been carried out for a natural gas combustion plant which combines cryogenic enriched oxygen production $\left(\mathrm{O}_{2}\right.$ purity $40-90 \%$ ) and membrane postcombustion capture. A series of simplifying assumptions has been made and a conceptual design analysis has been performed. It has been shown that the hybrid process can lead to a 35\% decrease of the overall energy requirement, providing that the optimal oxygen purity is used (typically 40-60\%) in combination with a membrane module with a $\mathrm{CO}_{2} / \mathrm{N}_{2}$ selectivity of 50 or more (a performance which has been already reported by several authors on this mixture).

The concept of a hybrid process, based on a combination of an enriched oxygen production step and a capture step can thus be seen as promising and logically calls for an extended analysis. This should be covered in future work according the following items:

(i) First, this study has been restricted to natural gas as fuel. The same analysis should be performed with other fossil fuels, especially coal, which is most often used for power plant operation and generates more concentrated $\mathrm{CO}_{2}$ flue gases compared to natural gas.

(ii) Energy requirement only has been investigated and taken as the objective variable. It is obvious that the capital cost of the process should be also taken into account. Even though the use of two processes in place of a single one (i.e. oxycombustion or postcombustion capture) may look at first glance as very unfavourable, it is important to stress that oxycombustion already requires concentration and drying operations after combustion $[4,24]$. It could be that the membrane concentration module remains of limited size, compared to the dryer.

(iii) An ideal stoichiometry and binary mixtures only have been considered. The incidence of inert gases (such as argon), and of excess oxygen should be also taken into account. NOx formation in the combustion process should also be considered, as well as the fate of these compounds in the membrane separation module. These observations lead to a more complex flue gas composition, with several minor compounds and a multicomponent membrane separation simulation.

(iv) There are constraints in varying the oxygen concentration in the combustion air due to temperature constraints in the furnaces, boilers, gas turbines or engines and emission constraints. This means that one has to operate with an excess amount of oxidant, as is already the case for current gas turbines. Such issues can be counteracted by the use of recycle flue gas, similar to an oxyfuel process. The impact of changing oxidant concentrations will affect the combustion process conditions. The incidence of these modifications on the process performances should be explored.

(v) A single module, single stage compressor has been assumed for the membrane operation. No energy recovery system such as an expander has been taken into account, at the opposite to other studies with membrane processes [19]. These various options could slightly decrease the energy requirement of the membrane process, and consequently improve the interest of the hybrid process.

\section{Notation \\ E Overall energy requirement (GJ per ton of $\mathrm{CO}_{2}$ ) \\ $n \quad$ Number of carbon atoms in the hydrocarbon (-) \\ $P^{\prime} \quad$ membrane module upstream side pressure (bar) \\ $P^{\prime \prime} \quad$ membrane module downstream side pressure (bar) \\ $R \quad$ carbon dioxide recovery ratio (-) \\ $\mathrm{R} \quad$ perfect gas constant $\left(8.314 \mathrm{~J} \mathrm{~mol}^{-1} \mathrm{~K}^{-1}\right)$ \\ $T \quad$ temperature $(\mathrm{K})$ \\ $W_{\text {min }} \quad$ Minimal work of separation $\left(\mathrm{J} \mathrm{mol}^{-1}\right)$, Eqn. (1) \\ $W_{\min }^{\prime} \quad$ Minimal work of extraction $\left(\mathrm{J} \mathrm{mol}^{-1}\right)$, Eqn. (2) \\ $W_{\text {min }}^{\prime \prime} \quad$ Minimal work of concentration $\left(\mathrm{J} \mathrm{mol}^{-1}\right)$, Eqn. (3) \\ $x$ \\ $y \quad$ carbon dioxide mole fraction in the permeate side (-)}

$\begin{array}{ll}\text { Greek letters } \\ \alpha & \text { membrane separation factor }(-) \\ \gamma & \text { adiabatic gas expansion coefficient }(-) \\ \eta^{\prime} & \text { compressor isentropic efficiency }(-) \\ \eta & \text { separation process overall energy efficiency }(-)\end{array}$

\section{Acknowledgements}

The financial support of the Centre National de la Recherche Scientifique (Cocase grant from Programme Energie of the CNRS) is gratefully acknowledged. E.F. thanks Paul Feron (TNO) and Etienne Lebas (IFP) for stimulating and inspiring discussions on this project.

\section{References}

[1] O. Davidson, B. Metz, Special Report on Carbon Dioxide Capture and Storage, International Panel on Climate Change, Geneva, Switzerland, 2005 $<$ http://www.ipcc.ch>.

[2] C.M. White, Separation and capture of $\mathrm{CO}_{2}$ from large stationary sources and sequestration in geological formations, J. Air Waste Manage. Assoc. 53 (2003) 645-715.

[3] M. Simmonds, P. Hurst, M.B. Wilkinson, C. Watt, C.A. Roberts, A study of very large scale post combustion $\mathrm{CO}_{2}$ capture at a refining \& petrochemical complex, 2003 <http://www.co2captureproject.org>

[4] D. Singh, E. Croiset, P.L. Douglas, M.A. Douglas, Techno-economic study of $\mathrm{CO}_{2}$ capture from an existing coal-fired power plant: MEA scrubbing vs $\mathrm{O}_{2} / \mathrm{CO}_{2}$ recycle combustion, Energy Conversion Manage. 44 (2003) 3073.

[5] P. Deschamps, P.A. Pilavachi, Research and development actions to reduce $\mathrm{CO}_{2}$ emissions within the European Union, Oil Gas Sci. Technol. 59 (3) (2004) 323-330.

[6] J.L. Humphrey, G.E. Keller, Separation Process Technology, MacGraw Hill Ed, New York, 1997.

[7] E.N. Lightfoot, M.C.M. Cockrem, What are dilute solutions? Separat. Sci. Technol. 22 (1987) 165-189.

[8] S.P. Kaldis, G. Skrodas, G.P. Sakellaropoulos, Energy and capital cost analysis of $\mathrm{CO}_{2}$ capture in coal IGCC processes via gas separation membranes, Fuel Process. Technol. 85 (2004) 337.

[9] F. Notaro, Advances in ambient temperature air separation, in: Proceedings of the Meeting on Air Separation Technology, Munich, Germany. Refrigeration Science and Technology Proceedings, International Institute of Refrigeration (ISBN 2-903633-86X), 1996. 
[10] G. Göttlicher, The energetics of carbon dioxide capture in power plants, US Department of Energy, National Energy Technology Laboratory, 2004.

[11] A. Tuberga, Oxygen from a jointed PSA and cryogenic process, in: Refrigeration Science and Technology. Proceedings of the Meeting of Commission A3, International Institute of Refrigeration.(ISBN 2-903633-45-2), 1996.

[12] R. Kumar, Vacuum swing adsorption process for oxygen production. A historical perspective, Separat. Sci. Technol. 31 (7) (1996) 877-893.

[13] R. Baker, I. Roman, H.K. Lonsdale, Liquid membranes for the production of oxygen enriched air, J. Membr. Sci. 31 (1) (1987) 15-29.

[14] R.W. Baker, Future directions of membrane gas separation technology, Ind. Eng. Chem. Res. 41 (2002) 1393.

[15] B.D. Bhide, A. Stern, A new evaluation of membrane process for the oxygen enrichment of air. II. Effects of economic parameters and membrane properties, J. Membr. Sci. 62 (1991) 37-58.

[16] G.R. Rigby, H.C. Watson, Application of membrane gas separation to oxygen enrichment of diesel engines, J. Membr. Sci. 87 (1994) 159-169.

[17] W.J. Koros, Evolving beyond the thermal age of separation processes: membranes can lead the way, AIChE J. 50 (10) (2004) 2326.
[18] D. Aaron, C. Tsouris, Separation of $\mathrm{CO}_{2}$ from flue gas: a review, Separat. Sci. Technol. 40 (2005) 321-348.

[19] J.P. Van der Sluis, C.A. Hendriks, K. Blok, Feasability of polymer membranes for carbon dioxide recovery from flue gases, Energy Conversion Manage. 33 (1992), $5-8,429$.

[20] T.M. Ho, G. Leamon, G.W. Allinson, D.E. Wiley, Economics of $\mathrm{CO}_{2}$ and mixed gas geosequestration of flue gas using gas separation membranes, Ind. Eng. Chem. Res. 45 (2006) 2546-2552.

[21] E. Favre, Carbon dioxide recovery from post combustion processes: can gas permeation membranes compete with absorption? J. Membr. Sci. 294 (2007) 50-59.

[22] R. Bounaceur, N. Lape, D. Roizard, C. Vallières, E. Favre, Membrane processes for post-combustion carbon dioxide capture: a parametric study, Energy 31 (14) (2006) 2220-2234.

[23] R. Zolandz, G.K. Fleming, in: W.S. Ho, K.K. Sirkar (Eds.), Gas Permeation Applications. Membrane Handbook, Van Nostrand Reinhold, New York, 1992.

[24] D.G. Jandjel, Select the right compressor, Chem. Eng. Prog. 7 (2000) 15-30. 